\title{
Bernard Lavallé
}

\section{OpenEdition}

Journals

Edición electrónica

URL: http://journals.openedition.org/bifea/5685

DOI: 10.4000/bifea.5685

ISSN: 2076-5827

\section{Editor}

Institut Français d'Études Andines

\section{Edición impresa}

Fecha de publicación: 1 mayo 2005

Paginación: 135

ISSN: 0303-7495

\section{Referencia electrónica}

Bernard Lavallé, «Intelectuales y poder en la Historia del Perú », Bulletin de l'Institut français d'études andines [En línea], 34 (1) | 2005, Publicado el 08 abril 2005, consultado el 01 diciembre 2020. URL : http://journals.openedition.org/bifea/5685 ; DOI : https://doi.org/10.4000/bifea.5685

\section{(c) $)(1)(9)$}

Les contenus du Bulletin de l'Institut français d'études andines sont mis à disposition selon les termes de la licence Creative Commons Attribution - Pas d'Utilisation Commerciale - Pas de Modification 4.0 International. 


\section{INTELECTUALES Y PODER EN LA HISTORIA DEL PERÚ Coloquio internacional, 14-16 de diciembre de 2004 Pontificia Universidad Católica del Perú}

Después de una magistral conferencia inaugural a cargo de la profesora Jean Franco de la universidad de Columbia, el simposio arriba indicado reunió a unos cuarenta ponentes procedentes mayoritariamente del Perú, pero también de varios países del subcontinente y de universidades de los Estados Unidos. En ocho paneles, éstos abarcaron un gran número de temáticas, por eso mismo muy diversas: la situación y actuación de los intelectuales durante la época colonial, los intelectuales y el proyecto nacional decimonónico, los intelectuales y el nacimiento del Estado, las relaciones de la intelectualidad peruana con sus homólogas extranjeras, las ambigüedades y a veces contradicciones de las actitudes de los intelectuales frente al poder, y su papel, en algunos casos relevante, de intermediarios culturales.

Los tres días de apretadas sesiones se clausuraron con dos mesas redondas en las que ocho conocidos intelectuales del Perú actual, comprometidos en diversos sectores de actividad social o cultural y procedentes de horizontes ideológicos diferentes, debatieron ante un nutrido público en torno a «la idea del Perú», y reflexionaron, desde sus respectivas perspectivas, sobre la actualidad peruana, las complicadas y dolorosas vías seguidas por el país a lo largo de las últimas décadas y los retos que le esperan de cara al porvenir.

La mayoría de las ponencias evidenciaron de manera muy esclarecedora los derroteros actualmente seguidos por las nuevas investigaciones acerca de los siglos XIX y XX en el Perú, en los diversos campos de las ciencias sociales; y mostraron efectivamente, en muchos aspectos, una evidente renovación, en particular gracias a los aportes de la sociología, de la filosofía y de la ciencia política.

Como sucede a menudo, los problemas de este evento provinieron tal vez de la misma riqueza y variedad de las ponencias presentadas. En primer lugar, porque varios paneles igualmente atractivos funcionaban paralelamente. Después, porque la mayoría de las ponencias se centraron en casos y ejemplos y no pudieron dedicar el tiempo suficiente a teorizaciones y modelizaciones que contribuyesen a estructurar las perspectivas presentadas. Los comentaristas consiguieron en general establecer los vínculos entre las problemáticas abordadas dentro de cada panel, e intentaron, a veces con una notable brillantez y una fuerza muy sugerente, acercarse a definiciones, o indicaron vías tranversales de análisis globales sin duda bastante provechosas, por lo cual es de esperar que dichos comentarios se puedan publicar también en las actas del simposio que se anuncian.

Bernard LAVALLÉ 